\title{
Using Stories to Communicate Individual Risk for Opioid Prescriptions: Study Protocol for the Life STORRIED Multicenter Randomized Clinical Trial
}

\section{Zachary F Meisel}

Center for Emergency Care Policy and Research, Perelman School of Medicine, University of Pennsylvania https://orcid.org/0000-0001-8474-7993

\section{Esha Bansal}

Center for Emergency Care Policy and Research, Perelman School of Medicine, University of

Pennsylvania

\section{Marilyn M Schapira}

Department of General and Internal Medicine, University of Pennsylvania and the Veteran's Administration Medical Center

Jeanmarie Perrone

Center for Emergency Care Policy and Research, Perelman School of Medicine, University of Pennsylvania

\section{Carolyn C Cannuscio}

Center for Emergency Care Policy and Research, Perelman School of Medicine, University of Pennsylvania

\section{Karin V Rhodes}

Department of Population Health Management, Donald and Barbara Zucker School of Medicine

\section{Erik P Hess}

Department of Emergency Medicine, University of Alabama at Birmingham

\section{Erica B Goldberg}

Center for Emergency Care Policy and Research, Perelman School of Medicine, University of

Pennsylvania

\section{Melissa A Rogers}

Patient Investigator

\section{Jeffrey J Bell}

Patient Investigator

\section{Michael M Zyla}

Patient Investigator

\section{Sharon McCollum}

Patient Investigator

Abby R Dolan 
Center for Emergency Care Policy and Research, Perelman School of Medicine, University of Pennsylvania

\section{Frances S Shofer}

Center for Emergency Care Policy and Research, Perelman School of Medicine, University of Pennsylvania

\section{Method Article}

Keywords:

Posted Date: November 13th, 2018

DOI: https://doi.org/10.21203/rs.1.19/v1

License: (c) (i) This work is licensed under a Creative Commons Attribution 4.0 International License. Read Full License 


\section{Abstract}

Background: Prescription opioid abuse in the United States is a devastating public health crisis, of which many chronic opioid users were originally prescribed the medication for acute pain. Narrative enhanced risk communication may improve patient outcomes such as knowledge of opioid risk and opioid use behaviors in the setting of acute pain. Methods \& Design: Patients presenting to the acute care facilities of four geographically and ethnically diverse United States hospital centers with renal colic or musculoskeletal back pain will be eligible for this multicenter randomized clinical trial. A control group of patients receiving a standardized, general risk information sheet will be compared to two intervention groups, one receiving the risk information sheet plus a probabilistic opioid risk tool and another receiving the risk information sheet plus a narrative enhanced probabilistic opioid risk tool. We will study the effect of probabilistic and narrative enhanced opioid risk communication on: 1) knowledge as measured by risk awareness and treatment preferences for fewer opioids; 2 ) reduced use of opioids as measured by quantity of opioids taken, functional improvement, and repeat use of unscheduled visits for pain; 3 ) patient-provider alignment as measured by concordance between patient preference and finalized prescription plan and the presence of shared decision making. To assess these outcomes, we will administer baseline patient surveys during acute care admission and follow-up surveys at predetermined times during the ninety days after discharge. Discussion: This study seeks to assess the potential clinical role of narrative enhanced, risk-informed communication for acute pain management in acute care settings. This paper outlines the protocol used to implement the study and highlights crucial methodological, statistical, stakeholder involvement, and dissemination considerations.

\section{Background}

Opioid abuse in the United States is a devastating public health crisis, responsible for 64,000 overdose deaths per year and $\$ 78.5$ billion in health and social costs annually from prescription opioids alone [1, 2]. Notably, most chronic prescription opioid users were originally prescribed the medication for acute pain $[3,4]$.

With $42 \%$ of Emergency Department (ED) visits related to pain, acute care settings are vital locations for providers and patients to manage pain while reducing misuse of opioids [5]. In acute illness and recovery, inadequate pain management is associated with greater morbidity, lower patient satisfaction, and higher costs of care [6]. Nevertheless, younger age, illicit drug use, tobacco use, alcohol abuse, sexual abuse, and family history of drug and alcohol use are all risk factors for prescription drug abuse, along with social factors including unemployment, and mental health conditions such as depression, anxiety, and PTSD [7, 8].

In practice, providers often make therapeutic decisions, particularly around analgesia, without engaging patients about their risks. Moreover, when they do discuss the risks and benefits of specific options, the communication is frequently devoid of context and probabilistic in nature (presenting the likelihood of outcomes using either descriptive words or numbers) $[9,10]$. Probabilistic tools have been established as 
a common way to communicate information about risks and benefits to patients facing medical decisions. Furthermore, a recent emergency department randomized controlled trial demonstrated that a fact-based, literacy-appropriate information sheet alone did not improve patients' knowledge and safe use of opioid analgesics compared to usual care [11].

In this context, narrative communication can be an inexpensive, sustainable, and effective tool to promote engagement around health information and to enhance other forms of risk communication. A narrative is defined as a coherent story with an identifiable beginning, middle, and end that provides information about scene, characters and conflict; raises unanswered questions or unresolved conflict; and provides resolution [12]. Narratives have been noted to improve the communication of health information by holding people's attention and "transporting" their mental state [13,14].

Importantly, narratives have been shown to help clarify the values and trade-offs associated with risk in a more palatable manner than purely probabilistic facts alone [15]. Communicating risk using narratives has also been demonstrated to benefit subgroups with lower levels of education, literacy, and numeracy $[15,16,17,18,19,20]$. However, the role of narratives for communicating and translating risk evidence, specifically when attempting to improve pain treatment in acute care settings, has not been evaluated in a comparative manner. Furthermore, research on opioid prescriptions and use for acute, nonsurgical pain is severely lacking [6].

This study assesses two clinical interventions for opioid risk management among patients presenting to acute care settings with non-surgical musculoskeletal back pain or renal colic: a Probabilistic Risk Tool (PRT) and a Narrative Enhanced Risk Tool (NERT). The PRT is a risk communication intervention derived from the previously validated Opioid Risk Tool (ORT). Because narratives can enhance the effect of probabilistic communication $[16,17,18,19,20]$, the NERT combines the PRT (individualized risk) with a menu of video narratives, generated from past patients' stories, and displayed during the clinical encounter on a tablet computer.

This paper outlines the protocol used to implement the Life Stories for Opioid Risk Reduction in the ED (Life STORRIED) study, towards the goal of better understanding the clinical potential of narrativeenhanced, risk-informed communication in the setting of acute pain.

\section{Methods And Design}

The Life STORRIED study is a multicenter randomized clinical trial in the United States. Central ethical approval has been confirmed by The University of Pennsylvania institutional review board (reference approval no. 826673). Recruitment at other centers began once local ethical approval was obtained. The study began data collection on June 28, 2017.

Experimental Plan 
Eligible patients presenting to participating sites (emergency departments and associated urgent care and observation units) from four geographically distinct health systems will be randomized to one of three study arms:

1) Control group (Arm 1): Patients receive a standardized, general risk information sheet (General Risk Comparator) only. This study arm represents a risk communication approach commonly employed in clinical practice (Fig 1a).

2) PRT Intervention group (Arm 2): standardized, general risk information sheet plus a probabilistic opioid risk tool (Fig 1b).

3) NERT Intervention group (Arm 3): standardized, general risk information sheet plus a narrative enhanced probabilistic opioid risk tool (Fig 1c).

Patients will be stratified by complaint (renal colic or back/neck pain) and hospital center (University of Pennsylvania, Northwell Health, Mayo Clinic, or University of Alabama at Birmingham). Electronic consent, randomization within strata and hospital center will occur automatically through Way to Health (WTH), a web-based data collection platform for behaviorally oriented randomized clinical trials, during the enrollment process [21] using computer generated random numbers. All outcomes data are collected through the WTH platform, a secure, electronic database accessible only to researchers.

Opioid Risk Tool (ORT): For participants randomized into either intervention arm, WTH will display one of three ORT images - "at risk," "high risk," or "highest risk" for opioid misuse- based on participant responses to the ORT survey (Fig 2). Using a standardized script, study staff will discuss and interpret the ORT image with patients and provide a hard copy for participant possession.

Video narratives: For participants randomized to the narrative enhanced probabilistic risk tool arm, WTH will also display eight video narratives (Fig 3). Each narrative is a one- to three- minute, first-person, interview-based vignette of a patient or caregiver sharing personal perspectives and experiences of acute pain and opioid use and misuse. Together, the eight narrative videos feature patients of diverse backgrounds and risk levels to offer a balanced, varied commentary. The narratives are displayed in a menu format on a table computer and participants can watch any story by touching the picture of the storyteller. Study staff will encourage the participant to watch as many videos as desired, provide disposable earphones, and exit the room for privacy until the patient has completed viewing the videos.

The videos were developed by the research team to maximize factors such as identification with characters, perceived realism, normative values, and reinforcement. They were also reviewed for clarity and salience and tested through an iterative process with a core group of patient investigators and community stakeholders.

Study overview and objective 
The primary objective of this study is to determine whether risk-informed communication with or without a narrative-enhanced tool can improve functional outcomes and patient-centered outcomes in the domains of knowledge, opioid use, and patient/provider therapeutic alignment. Specifically, the study will measure the effectiveness of different risk communication strategies using the following outcomes (for a full list of primary and secondary measures, response type, collection points, and their relevance to patients and other stakeholders (see Table 1)):

1) Knowledge as measured by risk awareness and treatment preferences for fewer opioids, particularly among those at higher risk for addiction

2) Reduced use of opioids as measured by quantity of opioids taken, functional improvement, and repeat use of unscheduled visits for pain at 14 days

3) Patient/provider alignment as measured by concordance between patient preference and finalized prescription plan and the presence of shared decision making

We hypothesize that, compared to study patients receiving only a generalized risk information sheet or information sheet plus probabilistic risk communication tool, patients receiving narrative enhanced risk communication will:

1) Demonstrate greater knowledge as determined by awareness of risk for opioid dependency

2) a. Select a treatment plan with fewer opioids; b. Take fewer opioids for fewer days, while achieving the same degree of pain relief and improved functional status

3) a. Enjoy greater levels of concordance between the patient-preferred and provider-selected treatment plans; b. Engage in greater shared decision making with their provider.

\section{Setting}

Patients will be recruited from acute care settings (emergency department, urgent care or observation unit) in four United States hospital centers: the University of Pennsylvania in Philadelphia, Pennsylvania (east coast with an urban patient population), Northwell Health in Long Island, New York (east coast with a suburban patient population), the Mayo Clinic in Rochester, Minnesota (midwest with a rural patient population), and the University of Alabama in Birmingham, Alabama (southeast, with an urban patient population). These centers were selected to capture geographically and ethnically diverse patient populations and clinical practices.

\section{Sample population and recruitment}

Our sample population includes patients presenting to participating study sites with a chief complaint suggestive of acute renal colic or musculoskeletal neck or back pain. A trained project manager, research coordinator, or research associate will identify potentially eligible patients based on chart review and collaborate with the treating clinician to confirm patient eligibility for the study. Patients will be 
concurrently enrolled at all participating study sites five to seven days per week, whenever a trained enroller is available. Data audits, for completeness and accuracy are conducted monthly by the study team. Adverse events or other unintended effects of the trial will be reported immediately to the sponsor, the central IRB, and the office of human research at the home institution. Additionally, all important protocol modifications will be communicated to relevant parties, such as investigators, the IRB, participants and our funder PCORI.

\section{Selection of Participants}

The study inclusion criteria are as follows:

1) Patients 18-70 years of age presenting to an acute care setting AND

2) Chief complaint indicative of acute neck, back, and/or flank pain OR uncomplicated kidney stones AND

3) Capable of providing informed consent AND

4) English-speaking OR Spanish-speaking with English comprehension AND

5) Able to access a smartphone or email account regularly AND

6) The treating clinician anticipates discharge within 24 hours with a diagnosis of renal calculi or musculoskeletal back pain

Exclusion criteria include pregnancy, in police custody, under the influence of drugs or alcohol, mentally or cognitively unstable, suicidal, homicidal, or unable to take opioids or non-steroidal anti-inflammatories for any reason. Additionally, patients who display aberrant drug use behavior or have used opioid medications in the past 30 days - excluding opioids taken for the current condition within 48 hours of this acute care admission - are ineligible. Patients with a known history of chronic kidney disease $($ GFR $<60)$ are also ineligible, because they may not be able to take NSAIDS.

\section{Baseline enrollment (Day 0)}

Enrollment takes approximately thirty minutes and will be conducted in the flow of patient care. Once an eligible patient is identified via chart review and clinician consultation, study staff will use a standardized script to greet the patient, introduce the study, obtain written informed consent, and conduct baseline enrollment activities.

After providing informed consent, participants will answer questions from a series of surveys, including: 1) an informational profile of demographic data (gender, race, ethnicity, education level) [22, 23, 24]; 2) the Revised American Pain Society Patient Outcome Questionnaire [25]; 3) the 20-Item Short Form Survey from the Medical Outcomes Study [26]; 4) a tobacco use survey [23]; 5) the Opioid Risk Tool [27]; 6) the Screener and Opioid Assessment for Patients with Pain- Revised [28]; and 7) a pain relief preference 
survey. Participant responses to survey questions will be recorded in real time on a secure, passwordprotected iPad or tablet owned by the study. Study staff will administer surveys 1) through 3) and 7), whereas participants will complete surveys 4) through 6) directly on the study tablet computer due to the sensitive nature of these questions.

All participants will be given a generalized, fact-based risk information sheet for renal colic or neck/back pain, based on chief complaint. During enrollment, patients will have three minutes to familiarize themselves with the risk information sheet and ask questions to study staff.

\section{Participant follow-up (Days 1-7, Day 14, Day 90)}

On days one through seven and fourteen after enrollment, WTH will send participants automated email or text messages containing links to secure, online follow-up surveys. These brief surveys collect information on patient satisfaction and outlook [25], pain management strategies and functional outcomes, behavioral and functional characteristics [26, 29], medication use behaviors [30], quality of life [26], health literacy [31], and health numeracy [32]. Patients randomized to the narrative enhanced probabilistic risk tool arm will also receive messages encouraging them to continue to view the eight video narratives through an individualized WTH portal.

Ninety days after enrollment, study staff will contact participants by text or phone to conduct a 20-minute follow-up survey of the above attributes, as well as recall of opioid risk level and/or viewing of video narratives for patients randomized to the corresponding intervention arms.

\section{Patient and stakeholder engagement}

Patients and other key stakeholders are and will be engaged in this study throughout the entire research process. Four patients are formally involved in this study as Patient Investigators, full members of the core research team who provide perspective on research questions, methodologies, and patient-related outcomes. As current and former patients presenting with acute and/or chronic pain, Patient Investigators have unique and extensive input including diverse experiences with opioids. Additionally, the UPHS Patient and Family Education Committee, a formal group of hospital staff, patient advocates and community members who meet regularly to help patient and their families navigate hospital care, will provide study input. These stakeholders will also be engaged in the interpretation and dissemination of study findings as the trial progresses.

Text and email reminders are used to promote continuous engagement and follow up among study participants. Small cash incentives are used to maximize retention and promote follow up. All subjects are eligible to receive up to $\$ 50$ dollars for completing enrollment and follow up surveys. For the 90 day survey, if the subjects do not respond to the electronic reminders, research staff will call the participant to remind them to complete survey and, if necessary, to conduct the surveys by telephone.

All study staff will complete IRB certified training regarding human subjects' protection and will be thoroughly trained and supervised in the conduct of the research protocol. A project manager, responsible 
for general study oversight, will ensure all study procedures are followed and that any issues are brought to the attention of the investigators and resolved in a timely manner. Enrollment staff including research coordinators and research associates will be trained to demonstrate sensitivity to the pain experiences of patients and to neutrally present the intervention tools. Scripts and role playing will be used when training enrollment staff about how to approach patients, present the study, and maintain a nonjudgmental, neutral approach to collecting information on the amount and type of pain medication taken, history of substance abuse, and other sensitive psychosocial risks.

Statistical Analysis: Data will be analyzed in an intention to treat fashion. Standard statistical tests (2 and ANOVA or Kruskal Wallis test) will be performed to determine outcome distributions and whether patients differ with regard to demographics in the 3 study groups. A data monitoring board was not needed for this study as due to the anticipated low risk of the communication-based interventions and was approved by the central IRB. The investigators will have final access to the trial dataset. There are no contractual limitations to the investigators' access to these data. The following statistical techniques will be employed for each of our 3 goals of the study:

1. To demonstrate greater knowledge of risk for opioid dependency, concordance between individual risk as measured by the ORT, and follow-up at 2 weeks and three months about their recall of their risk category (measured by at risk, high risk, highest risk) and corresponding risk percentage $(6 / 100,28 / 100$, or 91/100), a Cohen's weighted kappa will be calculated for NERT \& PRT treatment groups, and then compared using a 2-sample Z-test and/or confidence intervals for the difference. Additional analyses will include dichotomizing concordance (concordant/discordant) as the outcome and developing logistic regression models including treatment arm, demographics (age, gender, ethnicity), and risk category. This will allow for comparison of NERT \& PRT treatment groups while adjusting for potential confounders.

2. To test the hypothesis that patients in the NERT group will take significantly less morphine equivalents than patients in PRT or control group, the primary analytic technique will be a Poisson (log-linear) regression or a Negative Binomial (ZINB) regression [33]. Models will be developed using SAS procedures GENMOD or COUNTREG using a log link and Poisson or a ZINB distribution. All models will be adjusted for baseline pain level, condition, and any complications, as well as possible modifiers/confounders such as age, gender, race, education, employment, insurance, income (SES), and marital/relationship status. To assess differences in number of days to no/minimal pain, number of days to cessation of opioid use, and time to return to functional status over the 3-month study period among the 3 treatment arms utilizing Kaplan-Meier curves and Cox proportional-hazard models. The log rank test will be used to assess differences in rate of cessation of opioid use and rate of return to functionality between the 3 treatment groups. Additionally, at the 3-month interview, functionality will be assessed with MOS-20 scales [25]. For this analysis, a 2-way ANOVA (group and condition as main effects) will be used.

3. To assess trust in the provider using the trust in physician scale (range of scores 11-55) [34] [35], and patient shared decision making using the CollaboRATE scale [36], a 2-way ANOVA at 3 months and at discharge, respectively will be used. To test the hypothesis that patients in the NERT group will have 
greater satisfaction with adequacy of pain management compared to PRT and control groups, 2 analytic techniques will be used. Satisfaction will be assessed using selected items from the American Pain Society Patient Outcome Questionnaire. To assess differences in the absolute score at 2 weeks and 3 months between the 3 treatment arms, an analysis of covariance will be performed with treatment group and condition as main effects, an interaction term crossing approach with condition, and covaried on baseline scores. In addition to this analysis, patient satisfaction will be dichotomized; 1-3 (not satisfied), 4-6 (satisfied) and a generalized linear model (SAS GLM procedure) with a log link, Gaussian or binomial error, and robust estimates of the standard errors of the model coefficients will be employed [37]. Finally, to assess agreement between Patient Preference and Provider Decision, a Cohen's weighted kappa will be calculated for each treatment arm.

Sample Size and Power Calculation: To determine the number of patients needed in each group for sufficient sample size we considered one of the primary outcomes measured in 2 ways (\# of morphine equivalents at 14 days, \# of days to no opioids). The final sample size was based on the number of days (rate) to no opioid use as this was the largest sample size needed to detect a clinically meaningful effect between PRT and NERT. Using a 2-sided log-rank test with an overall starting sample size of 1100 subjects achieves $80 \%$ power at a 0.05 significance level to detect a hazard ratio of 0.46 when the proportion not taking opioids at 2 weeks in the PRT group is 0.70 (an effect size as small as 15\%) and the loss to follow-up (LTF) is $20-25 \%$. Using a conservative estimate of a final sample size, we will have more than sufficient power $(>80 \%)$ to detect, a difference in number of morphine equivalents at 14 days as small as six, $5 \mathrm{mg}$ doses of oxycodone.

For the control arm, at least 300 patients will be enrolled. Using an effect size of $10-15 \%$ difference in proportions, which we considered to be clinically meaningful and also obtainable based on our pilot data, and conservatively estimating a $20-25 \%$ loss to follow-up in this group, we will have sufficient power with sample size 225 to evaluate a $10 \%$ difference assuming that $95 \%$ and $85 \%$ will no longer be taking opioids at 2 weeks in the NERT vs control group, respectively.

\section{Discussion}

In the United States, prescription opioid misuse affects over 2 million people and is responsible for more than 1,000 emergency department visits per day [38]. Simultaneously, emergency medicine providers face tremendous pressure to prescribe opioids for pain management, and are among the top opioid medication prescribers for patients under 40 years of age based on the number of prescriptions. In this context, there exists gaps in knowledge about the clinical value of prescription risk communication methods. Researchers have sought to validate opioid risk tools for individual patients, but have not explored how these risk tools work or how they can be used from the patient's perspective $[39,40]$.

This paper describes the Life STORRIED study protocol used to implement a multicenter, randomized clinical trial for evaluating the clinical potential of different risk communication strategies, with the goal of optimizing patient and provider decision-making about opioid use. 
This study is significant to patients and providers for at least two reasons. First, achieving adequate relief from acute pain while balancing addiction risks and side effects of prescription opioids is a major challenge for patients and providers. Acute pain management contributes largely to the United States crisis of prescription opioid abuse, which often begins with prescriptions for acute pain and is costly and harmful to families, communities, and society as a whole. Second, patients are frequently exposed to either under- or over- treatment of pain and have different risk profiles for opioid misuse, realities that may impact the appropriateness of various analgesics.

A recent systematic review on opioid dependence after exposure for pain relief concluded that there are not enough studies focused on acute pain and that studies of opioid use for acute pain control are almost uniformly of poor quality [38]. Indeed, most opioid guidelines are focused on the treatment of chronic pain. Another systematic review stated that "research on pain management in nonsurgical, nonmalignant acute pain is sparse." This is a major problem because poor pain management is associated with greater morbidity, lower patient satisfaction, and higher costs of care [6].

Furthermore, this study is clinically novel for at least three reasons. First, it addresses patients in acute care settings with acute pain, a diverse population at risk for opioid dependency and repeated use of emergency care. This common presentation is severely under-investigated, as the vast majority of research on prescription opioids focuses on patients with chronic pain in primary and longitudinal care settings. Second, this research addresses communication and patient decision support in acute care settings, an important yet also under-investigated area. Third, this study addresses the pervasive knowledge gap of narrative-enhanced risk communication in the setting of daily acute care decisionmaking about pain management. Narrative based communication tools represent a novel way to communicate risk to patients but have not yet been comparatively explored in the settings of emergency care or for pain treatment $[15,16,17,18,19,20]$.

The goal of this study is to provide crucial and currently lacking evidence about the value of personal narratives in communicating and managing opioid risk in acute care patients. Ultimately, this study aims to facilitate the creation of a clinically effective and accessible tool to guide pain management decisionmaking in acute care settings, in the setting of the modern prescription opioid abuse crisis.

\section{Declarations}

\section{Ethics approval and consent to participate}

All enrollees provided full consent as described. This protocol has been approved by the IRB from the University of Pennsylvania.

\section{Consent for publication}

Individuals whose faces are shown as part of Figure 3 signed written consent forms to release their video narratives and their images to be published. 
All relevant data and material will be made public through the Patient Centered Outcomes Research Institute.

\section{Competing interests}

The authors report no relevant competing interests.

\section{Funding}

The study is funded by the Patient Centered Outcomes Research Institute (PCORI/ CDR-1511-33496). Original Trial title: The comparative effectiveness of probabilistic versus patient narrative: enhanced risk communication for pain management following acute care

\section{Trial Status}

Recruitment of participants for Protocol 826673 began on 28 June 2018 and is expected to be completed 1 March 2019.

\section{Authors' contributions}

ZFM conceived of the study. ZFM, MMS, JP, CC, KVR, EPH, MAR, JJB, MMZ, SM, and FSS developed the initial protocol. EBG adapted and contributed to the development the final protocol. FSS performed the statistical and power calculations. ZFM EB and FSS wrote the majority of manuscript. All authors provided input and edits to the manuscript.

Acknowledgements

Not applicable

\section{Table 1. Table Of Outcomes And Statistical Measures}

\section{References}

1] https://www.drugabuse.gov/related-topics/trends-statistics/overdose-death-rates

2] Florence CS, Zhou C, Luo F, Xu L. The Economic Burden of Prescription Opioid Overdose, Abuse, and Dependence in the United States, 2013. Med Care. 2016;54(10):901-906.

doi:10.1097/MLR.0000000000000625.

3] Portenoy RK, Foley KM. Chronic use of opioid analgesics in non-malignant pain: Report of 38 cases. 


\begin{tabular}{|c|c|c|c|c|c|}
\hline Outcome & Measure & $\begin{array}{l}\text { Collection } \\
\text { Point }\end{array}$ & $\begin{array}{l}\text { Response } \\
\text { Type/Analysis }\end{array}$ & Statistical Test & $\begin{array}{l}\text { Why is this Patient Centered and Relevant for patients? } \\
*\end{array}$ \\
\hline \multicolumn{6}{|c|}{ Primary Patient Reported Outcome } \\
\hline $\begin{array}{l}\text { Agreement } \\
\text { with Risk and } \\
\text { Risk Recall }\end{array}$ & $\begin{array}{l}\text { Opioid Risk } \\
\text { Tool \& Risk } \\
\text { Assessment } \\
\text { Recall }\end{array}$ & $\begin{array}{l}\text { Baseline } \\
\text { and Day } \\
14 \\
\text { And } 3 \\
\text { Months }\end{array}$ & $\begin{array}{l}\text { Ordinal (3 } \\
\text { Options) for } \\
\text { Baseline Risk } \\
\text { and Risk } \\
\text { Recall }\end{array}$ & $\begin{array}{l}\text { Cohen's weighted } \\
\text { kappa (within } \\
\text { treatment arm) } c^{2} \\
\text { tests (crude } \\
\text { agreement) }\end{array}$ & $\begin{array}{l}\text { ORT is a brief screener allowing patients to } \\
\text { confidentially enter their own history to } \\
\text { determine the probability of becoming addicted } \\
\text { to opioids. Asking patients to recall their risk } \\
\text { level/score will assess patient awareness and } \\
\text { the impact on their chosen pain relief method. }\end{array}$ \\
\hline $\begin{array}{l}\text { Days to no } \\
\text { opioid use }\end{array}$ & $\begin{array}{l}\text { Number of } \\
\text { pain meds } \\
\text { taken daily }\end{array}$ & $\begin{array}{l}\text { Days 1-2, } \\
4-6,14 \text {, } \\
\text { and } 3 \\
\text { Months }\end{array}$ & $\begin{array}{l}\text { Continuous (\# } \\
\text { pills of each } \\
\text { type) }\end{array}$ & $\begin{array}{l}\text { Kaplan Meier \& } \\
\text { Proportional Hazards } \\
\text { (time to full } \\
\text { functionality) }\end{array}$ & $\begin{array}{l}\text { Directly reported by and measured by the } \\
\text { patient. Collection via text messaging or phone } \\
\text { allows for easy, flexible data collection. }\end{array}$ \\
\hline $\begin{array}{l}\text { Self-Reported } \\
\text { Opioid Use } \\
\text { (Total } \\
\text { morphine } \\
\text { equivalents) }\end{array}$ & $\begin{array}{l}\text { Type and } \\
\text { number of pain } \\
\text { meds taken } \\
\text { daily }\end{array}$ & $\begin{array}{l}\text { Days } 1-2 \text {, } \\
4-6,14 \text {, } \\
\text { and } 3 \\
\text { Months }\end{array}$ & $\begin{array}{l}\text { Continuous (\# } \\
\text { pills of each } \\
\text { type) }\end{array}$ & $\begin{array}{l}\text { Zero Inflated Negative } \\
\text { Binomial, or Zero } \\
\text { Inflated Poisson } \\
\text { models }\end{array}$ & $\begin{array}{l}\text { Directly reported by and measured by the } \\
\text { patient. Collection via text messaging or phone } \\
\text { allows for easy, flexible data collection. }\end{array}$ \\
\hline \multicolumn{6}{|c|}{ Secondary Patient Reported Outcomes } \\
\hline $\begin{array}{l}\text { Functional } \\
\text { Status }\end{array}$ & $\begin{array}{l}\text { Back Pain } \\
\text { Functional } \\
\text { Scale, MOS-20 }\end{array}$ & $\begin{array}{l}\text { Days 1, } 7 \text {, } \\
14, \\
\text { and } 3 \\
\text { Months, } \\
3 \text { Months }\end{array}$ & $\begin{array}{l}\text { Likert Scale } \\
(0-10) \\
\text { Composite } \\
\text { Score for } 5 \\
\text { items }(0-50)\end{array}$ & $\begin{array}{l}\text { Kaplan Meier \& } \\
\text { Proportional Hazards } \\
\text { (time to full functionality), } \\
\text { Random effects mixed } \\
\text { model to measure } \\
\text { clinically important } \\
\text { changes in functionality }\end{array}$ & $\begin{array}{l}\text { These validated surveys can detect differences in } \\
\text { reported functional status that are relevant to the } \\
\text { patient and their ability to return to their usual } \\
\text { activities (including work). }\end{array}$ \\
\hline $\begin{array}{l}\text { Patient } \\
\text { reported } \\
\text { preference for } \\
\text { pain relief }\end{array}$ & $\begin{array}{l}\text { Patient pain } \\
\text { relief } \\
\text { preference } \\
\text { survey }\end{array}$ & Baseline & $\begin{array}{l}5 \text { Options for } \\
\text { Patient } \\
\text { reported Pain } \\
\text { Relief } \\
\text { Preference }\end{array}$ & $\begin{array}{l}\text { Cochran-Armitage } c^{2} \\
\text { test for trend }\end{array}$ & $\begin{array}{l}\text { Directly reported by the patient. Allows patient } \\
\text { to report their preferences for pain relief, and } \\
\text { have these preferences relayed to their } \\
\text { providers. }\end{array}$ \\
\hline $\begin{array}{l}\text { Satisfaction } \\
\text { with Pain } \\
\text { Treatment }\end{array}$ & $\begin{array}{l}\text { Am. Pain Soc. } \\
\text { Patient } \\
\text { Outcome } \\
\text { Questionnaire }\end{array}$ & $\begin{array}{l}\text { Baseline, } \\
\text { Days 1, 7, } \\
14 \text { and } 3 \\
\text { Months }\end{array}$ & $\begin{array}{l}\text { Likert Scale } \\
(1-6) \\
\text { Dichotomous } \\
\text { (satisfied v. } \\
\text { not satisfied) } \\
\end{array}$ & $\begin{array}{l}\mathrm{C}^{2} \text { tests \& Mantel Haenzel } \\
\text { summary statistics } \\
\text { GLM with log linear link }\end{array}$ & $\begin{array}{l}\text { Pain Relief is an important part of acute medical care; } \\
\text { Patients indicate that Satisfaction with Treatment is } \\
\text { multi-faceted and individualized to their own priorities. }\end{array}$ \\
\hline $\begin{array}{l}\text { Trust in } \\
\text { Provider }\end{array}$ & $\begin{array}{l}\text { Trust in } \\
\text { Physician } \\
\text { Scale }\end{array}$ & Day 7 & $\begin{array}{l}\text { Likert Scale } \\
(1-5) \\
\text { Composite } \\
\text { Score for } 11 \\
\text { items }(11-55)\end{array}$ & $\begin{array}{l}\text { ANOVA or Kruskal Wallis } \\
\text { test }\end{array}$ & $\begin{array}{l}\text { Allows Patient to report their perception of their } \\
\text { provider. Patients are more likely to be adherent to } \\
\text { medical care when they trust their physicians. }\end{array}$ \\
\hline $\begin{array}{l}\text { Follow-up } \\
\text { Visits for Pain }\end{array}$ & $\begin{array}{l}\text { Self-Report } \\
\text { additional } \\
\text { provider visits }\end{array}$ & $\begin{array}{l}\text { Day } 14 \\
\text { and } 3 \\
\text { Months }\end{array}$ & $\begin{array}{l}\text { Dichotomous } \\
\text { ( } / \mathrm{N} \text { visits; } \\
\mathrm{Y} / \mathrm{N} \text { provide } \\
\text { pain pills) }\end{array}$ & $\begin{array}{l}\mathrm{c}^{2} \text { test } \\
\text { GLM with log linear link }\end{array}$ & $\begin{array}{l}\text { Directly reported by and measured by the patient. } \\
\text { Patient reported need for follow-up visits to address } \\
\text { on-going pain potentially indicates inadequate pain } \\
\text { management. }\end{array}$ \\
\hline $\begin{array}{l}\text { Patient- } \\
\text { reported } \\
\text { measure of } \\
\text { shared }\end{array}$ & CollaboRATE & Day 1 & $\begin{array}{l}\text { Likert Scale } \\
(1-10)\end{array}$ & & $\begin{array}{l}\text { Allows patient to report their perception of the decision } \\
\text { making process with their provider. }\end{array}$ \\
\hline
\end{tabular}

Page 13/21 


\begin{tabular}{|c|c|c|c|c|c|}
\hline \multirow{3}{*}{$\begin{array}{l}\text { decision } \\
\text { making } \\
\text { Opioid misuse }\end{array}$} & \multirow[b]{3}{*}{$\begin{array}{l}\text { Current Opioid } \\
\text { Misuse } \\
\text { Measure }\end{array}$} & \multirow[b]{3}{*}{3 Months } & \multicolumn{2}{|r|}{$\begin{array}{l}\text { ANOVA or Kruskal } \\
\text { Wallis }\end{array}$} & \multirow[b]{3}{*}{ Directly measures current opioid misuse. } \\
\hline & & & & Test & \\
\hline & & & $\begin{array}{l}\text { Dichotomous } \\
\text { Score }(\geq 9+ \\
<9)\end{array}$ & $\begin{array}{l}\mathrm{C}^{2} \text { test } \\
\text { GLM with log linear link }\end{array}$ & \\
\hline \multicolumn{6}{|c|}{ Alignment Outcomes } \\
\hline $\begin{array}{l}\text { Agreement on } \\
\text { pain treatment } \\
\text { between } \\
\text { patient } \\
\text { preference } \\
\text { and provider } \\
\text { decision } \\
\end{array}$ & $\begin{array}{l}\text { Patient } \\
\text { Preference v. } \\
\text { EMR } \\
\text { Documentation }\end{array}$ & & $\begin{array}{l}5 \text { Options for } \\
\text { Patient } \\
\text { reported Pain } \\
\text { Preference \& } \\
\text { concordance } \\
\text { with provider } \\
\text { decision. }\end{array}$ & $\begin{array}{l}\text { Cohen's weighted kappa, } \\
\text { ICC* }^{*} \text { Bland Altman plots } \\
\text { (within tx arm) } \mathrm{C}^{2} \text { tests } \\
\text { (crude agreement) }\end{array}$ & $\begin{array}{l}\text { Linking Patient Preference with EMR data makes the } \\
\text { patient related outcomes above stronger and linked } \\
\text { with concrete clinical data. }\end{array}$ \\
\hline \multicolumn{6}{|l|}{$\begin{array}{l}\text { Covariates } \\
\text { (Subgroup } \\
\text { analyses) } \\
\end{array}$} \\
\hline Demographics & $\begin{array}{l}\text { GENACIS / } \\
\text { BFRSS } 2011 \\
\end{array}$ & Baseline & $\begin{array}{l}\text { Varies by } \\
\text { question }\end{array}$ & & \\
\hline Overall Health & $\begin{array}{l}\text { Self-Rated } \\
\text { Health }\end{array}$ & $\begin{array}{l}\text { Baseline } \\
\text { and } \\
3 \text { Months }\end{array}$ & $\begin{array}{l}\text { Likert Scale } \\
(1-5)\end{array}$ & & \\
\hline $\begin{array}{l}\text { Medical } \\
\text { Condition } \\
\text { (Back vs. } \\
\text { Renal Colic) } \\
\end{array}$ & $\begin{array}{l}\text { ICD-9 Code } \\
\text { \& Primary } \\
\text { Complain }\end{array}$ & Baseline & ICD-9 Codes & & \\
\hline $\begin{array}{l}\text { Medical } \\
\text { History }\end{array}$ & $\begin{array}{l}\text { Electronic } \\
\text { health record }\end{array}$ & Baseline & ICD-9 Codes & & \\
\hline $\begin{array}{l}\text { Risk for Opioid } \\
\text { Dependency }\end{array}$ & $\begin{array}{l}\text { Opioid Risk } \\
\text { Tool }\end{array}$ & Baseline & $\begin{array}{l}\text { Continuous } \\
\text { Score (0-26) } \\
\text { Risk Level } \\
\text { (High, } \\
\text { Medium, Low) } \\
\end{array}$ & & \\
\hline
\end{tabular}

Pain. 1986;25(2):171-186. doi:10.1016/0304-3959(86)90091-6.

4] J P, H J. Addiction Rare in Patients Treated with Narcotics. NEJM. 1980;302(2):123.

doi:10.1056/NEJM198001103020221.

5] Cantrill S V., Brown MD, Carlisle RJ, et al. Clinical policy: Critical issues in the prescribing of opioids for adult patients in the emergency department. Ann Emerg Med. 2012;60:499-525.

doi:10.1016/j.annemergmed.2012.06.013.

6] Helfand M, Freeman M. Assessment and management of acute pain in adult medical inpatients: a systematic review. Pain Med. 2009;10:1183-1199. doi:10.1111/j.1526-4637.2009.00718.x.

7] Edlund MJ, Martin BC, Devries A, Fan M-Y, Braden JB, Sullivan MD. Trends in use of opioids for chronic noncancer pain among individuals with mental health and substance use disorders: the TROUP study. 
Clin J Pain. 2010;26:1- 8. doi:10.1097/AJP.0b013e3181b99f35.

8] Turk DC, Swanson KS, Gatchel RJ. Predicting opioid misuse by chronic pain patients: a systematic review and literature synthesis. Clin J Pain. 24(6):497-508. doi:10.1097/AJP.0b013e31816b1070.

9] McCarthy DM, Cameron KA, Courtney DM, Adams JG, Engel KG. Communication about opioid versus nonopioid analgesics in the emergency department. J Opioid Manag. 11(3):229-236. doi:10.5055/jom.2015.0271.

10] McCarthy DM, Engel KG, Cameron KA. Conversations about analgesics in the emergency department: A qualitative study. Patient Educ Couns. January 2016. doi:10.1016/j.pec.2016.01.011.

11] McCarthy DM, Wolf MS, McConnell R, et al. Improving Patient Knowledge and Safe Use of Opioids: A Randomized Controlled Trial. Acad Emerg Med. 2015;22(3):331-339. doi:10.1111/acem.12600.

12] Hinyard LJ, Kreuter MW. Using Narrative Communication as a Tool for Health Behaviour Change: A Conceptual, Theoretical, and Empirical Overview. Heal Educ Behav. 2007.

13] Kreuter MW, Green MC, Cappella JN, et al. Narrative communication in cancer prevention and control: a framework to guide research and application. Ann Behav Med. 2007;33:221-235. doi:10.1080/08836610701357922.

14] Green MC, Brock TC. The role of transportation in the persuasiveness of public narratives. J Pers Soc Psychol. 2000;79(5):701-721. doi:10.1037/0022-3514.79.5.701.15] 47

15] Winterbottom A, Bekker HL, Conner M, Mooney A. Does narrative information bias individual's decision making? A systematic review. Soc Sci Med. 2008;67:2079-2088.

doi:10.1016/j.socscimed.2008.09.037.

16] Bekker HL, Winterbottom AE, Butow $P$, et al. Do personal stories make patient decision aids more effective? A critical review of theory and evidence. BMC Med Inform Decis Mak. 2013;13 Suppl 2:S9. doi:10.1186/1472-6947-13-S2-S9.

17] Entwistle VA, France EF, Wyke S, et al. How information about other people's personal experiences can help with healthcare decision-making: A qualitative study. Patient Educ Couns. 2011;85(3). doi:10.1016/j.pec.2011.05.014.

18] Shaffer VA, Zikmund-Fisher BJ. All Stories Are Not Alike: A Purpose-, Content-, and Valence-Based Taxonomy of Patient Narratives in Decision Aids. Med Decis Mak. 2012:4-13. doi:10.1177/0272989X12463266.

19] Wise M, Han JY, Shaw B, McTavish F, Gustafson DH. Effects of using online narrative and didactic information on healthcare participation for breast cancer patients. Patient Educ Couns. 2008;70(3):348356. doi:10.1016/j.pec.2007.11.009. 
20] Jibaja-Weiss ML, Volk RJ. Utilizing computerized entertainment education in the development of decision aids for lower literate and naïve computer users. J Health Commun. 2007;12(7):681-697. doi:10.1080/10810730701624356.

21] Way to Health. Study data were collected and managed using the Way to Health research platform (https://waytohealth.org). Way to Health is a secure, web-based platform that automates many of the functions necessary for conducting clinical trials involving patient and clinician communication and engagement, remote monitoring, and behavioral interventions.

22] GENACIS gender, alcohol, and culture: an international study questionnaire. (2007). Retrieved March 16, 2017 form http://www.genacis.org/questionnaires/core.pdf.

23] ICF Macro, Office on Smoking and Health, Centers for Disease Control and Prevention (CDC). United States National Adult Tobacco Survey 2009-2010. Atlanta, United States: Office on Smoking and Health, Centers for Disease Control and Prevention (CDC).

24] Smith PC, Schmidt SM, Allensworth-Davies D, Saitz R. A Single-Question Screening Test for Drug Use in Primary Care. Arch Intern Med. 2010;170(13):1155-1160. doi:10.1001/archinternmed.2010.140

25] McNeill JA, Sherwood GD, Starck PL, Thompson CJ. Assessing Clinical Outcomes: Patient Satisfaction with Pain Management. Vol 16.; 1998. doi:10.1016/S0885-3924(98)00034-7.

26] Stewart, AL, Hays, RD, Ware, JE. The MOS short-form general health survey. Med. Care. 1988; 26:724735.

27] Boscarino J a., Rukstalis M, Hoffman SN, et al. Risk factors for drug dependence among out-patients on opioid therapy in a large US health-care system. Addiction. 2010;105(April 2009):1776-1782. doi:10.1111/j.1360-0443.2010.03052.x

28] Butler SF, Fernandez K, Benoit C, Budman SH, Jamison RN. Validation of the revised screener and opioid assessment for patients with pain (SOAPP®-R).J. Pain. 2008; 9 (4):360-372.

29] Stratford PW, Binkley JM, Riddle DL. Development and initial validation of the back pain functional scale. Spine (Phila Pa 1976). 2000;25(16):2095-2102. doi:10.1097/00007632-200008150-00015

30] Butler, SF, Budman, SH, Fernandez, KC, Houle, B, Benoit, C, et al. Development and validation of the Current Opioid Misuse Measure. PAIN. 2007; 130 (1-2):144-156

31] Chew, DL, Bradley, KA, Boyko, EJ, Brief questions to identify patients with inadequate health literacy. Family Medicine. 2004; 36(8): 588-594.

32] Fagerlin, A., Zikmund-Fisher, B.J., Ubel, P.A., Jankovic, A., Derry, H.A., \& Smith, D.M. Measuring numeracy without a math test: Development of the Subjective Numeracy Scale (SNS). Medical Decision Making, 2007: 27: 672-680. 
33] D. L. Zero-inflated Poisson regression, with an application to defects in manufacturing. . Technometrics. 1992; 34:1-14.

34] Thom, DH, Ribisl, KM, Stewart, AL, Luke, DA. Further validation and reliability testing of the Trust in Physician Scale. The Stanford Trust Study Physicians. Med Care. 1999;37:510-517. doi:10.1097/00005650-199905000-00010.

35] Anderson, LA, Dedrick, RF. Development of the Trust in Physician scale: a measure to assess interpersonal trust in patient-physician relationships. Psychol Rep. 1990;67:1091-1100. doi:10.2466/pr0.1990.67.3f.1091.

36] Elwyn, G, Barr PJ, Grande SW, Thompson R, Walsh T, Ozanne Em. Developing CollaboRATE: a fast and frugal patient-reported measure of shared decision making in clinical encounters. Patient Educ Couns. 2013; 93(1):102-7. doi: 10.1016/j.pec.2013.05.009

37] Lumley T KR, Ma S. Relative Risk Regression in Medical Research: Models, Contrasts, Estimators, and Algorithms. : UW Biostatistics Working Paper Series, Working Paper 293. ; 2006. Available from: http://www.bepress.com/uwbiostat/paper293/.

38] https://www.cdc.gov/drugoverdose/data/overdose.html

39] Jones T, Passik SD. A comparison of methods of administering the Opioid Risk Tool. J Opioid Manag. 2011;7:347-351. doi:10.5055/jom.2011.0075.

40] Wallace LS, Keenum AJ, Roskos SE. Comprehensibility and readability of patient self-administered opioid assessment screening tools. J Opioid Manag. 3(6):338-344.

\section{Figures}




\begin{tabular}{|c|c|c|c|c|c|c|c|c|c|c|c|}
\hline & & & \multicolumn{9}{|c|}{ STUDY PERIOD } \\
\hline & Enrolment & Allocation & \multicolumn{9}{|c|}{ Post-allocation } \\
\hline TIMEPOINT (DAYS) & 0 & 0 & 1 & 2 & 3 & 4 & 5 & 6 & 7 & 14 & 90 \\
\hline ENROLMENT: & $\mathrm{x}$ & $x$ & & & & & & & & & \\
\hline Eligibility screen & $\mathrm{x}$ & $\mathrm{x}$ & & & & & & & & & \\
\hline Informed consent & $\mathrm{x}$ & $\mathrm{x}$ & & & & & & & & & \\
\hline Allocation & $\mathrm{x}$ & $x$ & & & & & & & & & \\
\hline \multicolumn{12}{|l|}{ INTERVENTIONS: } \\
\hline [Arm 1: GRC] & $\mathrm{x}$ & $\mathrm{x}$ & & & & & & & & & \\
\hline [Arm 2: PRT] & $x$ & $\mathrm{x}$ & & & & & & & & & \\
\hline [Arm 3: NERT] & $\mathrm{x}$ & $\mathrm{x}$ & & & & & & & & & \\
\hline \multirow{4}{*}{$\begin{array}{r}\text { ASSESSMENTS: } \\
\text { [Agreement with Risk } \\
\text { and Risk Recall] } \\
\text { [Days to no opioid } \\
\text { Use] } \\
\text { [Self-reported Opioid } \\
\text { Use] }\end{array}$} & & & & & & & & & & & \\
\hline & * & $-x$ & & - & & & & & & $\mathrm{x}$ & $\mathrm{x}$ \\
\hline & & & س & $\Delta x$ & & $x$ & $x$ & $x$ & & $x$ & $x$ \\
\hline & & & $\mathrm{x}$ & $\mathrm{X}$ & & $\mathrm{x}$ & $\mathrm{x}$ & $\mathrm{x}$ & & $\mathrm{x}$ & $\mathrm{x}$ \\
\hline \multirow{3}{*}{$\begin{array}{r}\text { [Functional Status] } \\
\text { [Patient reported } \\
\text { preference for pain } \\
\text { relief] } \\
\text { [Satisfaction with } \\
\text { Pain Treatment] }\end{array}$} & & & $\mathrm{x}$ & & & & & & $\mathrm{x}$ & $\mathrm{x}$ & $\mathrm{x}$ \\
\hline & $\mathrm{x}$ & $\mathrm{x}$ & & & & & & & & & \\
\hline & $\mathrm{x}$ & $\mathrm{x}$ & $\mathrm{x}$ & & & & & & $\mathrm{x}$ & $\mathrm{x}$ & $\mathrm{x}$ \\
\hline \multirow{3}{*}{$\begin{array}{r}\text { [Trust in provider] } \\
\text { [Follow-up Visits for } \\
\text { Pain] } \\
\text { [Patient-reported } \\
\text { Measure of Shared } \\
\text { Decision Making] }\end{array}$} & & & & & & & & & $\mathrm{x}$ & & \\
\hline & & & & & & & & & & $\mathrm{x}$ & $\mathrm{x}$ \\
\hline & & & $\mathrm{x}$ & & & & & & & & \\
\hline
\end{tabular}

Figure 1

SPIRIT Figure. 


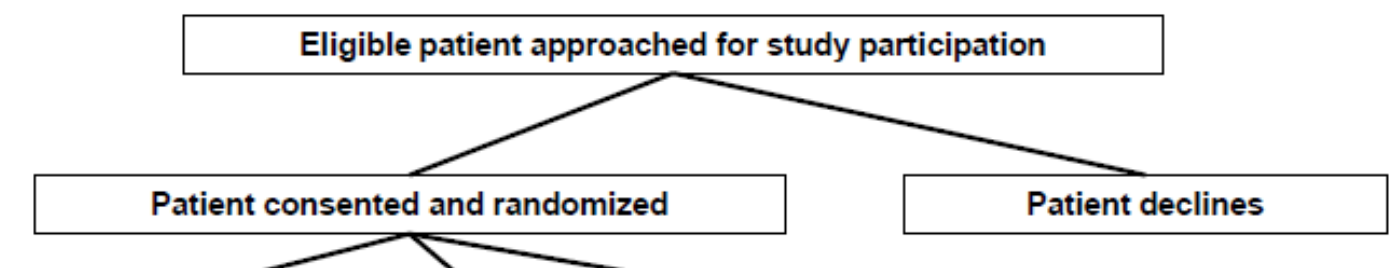

Arm 1

General Risk

Comparator

Arm 2

Probabilistic

Risk Tool

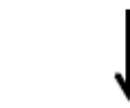

$\checkmark$

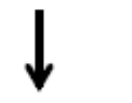

Arm 3
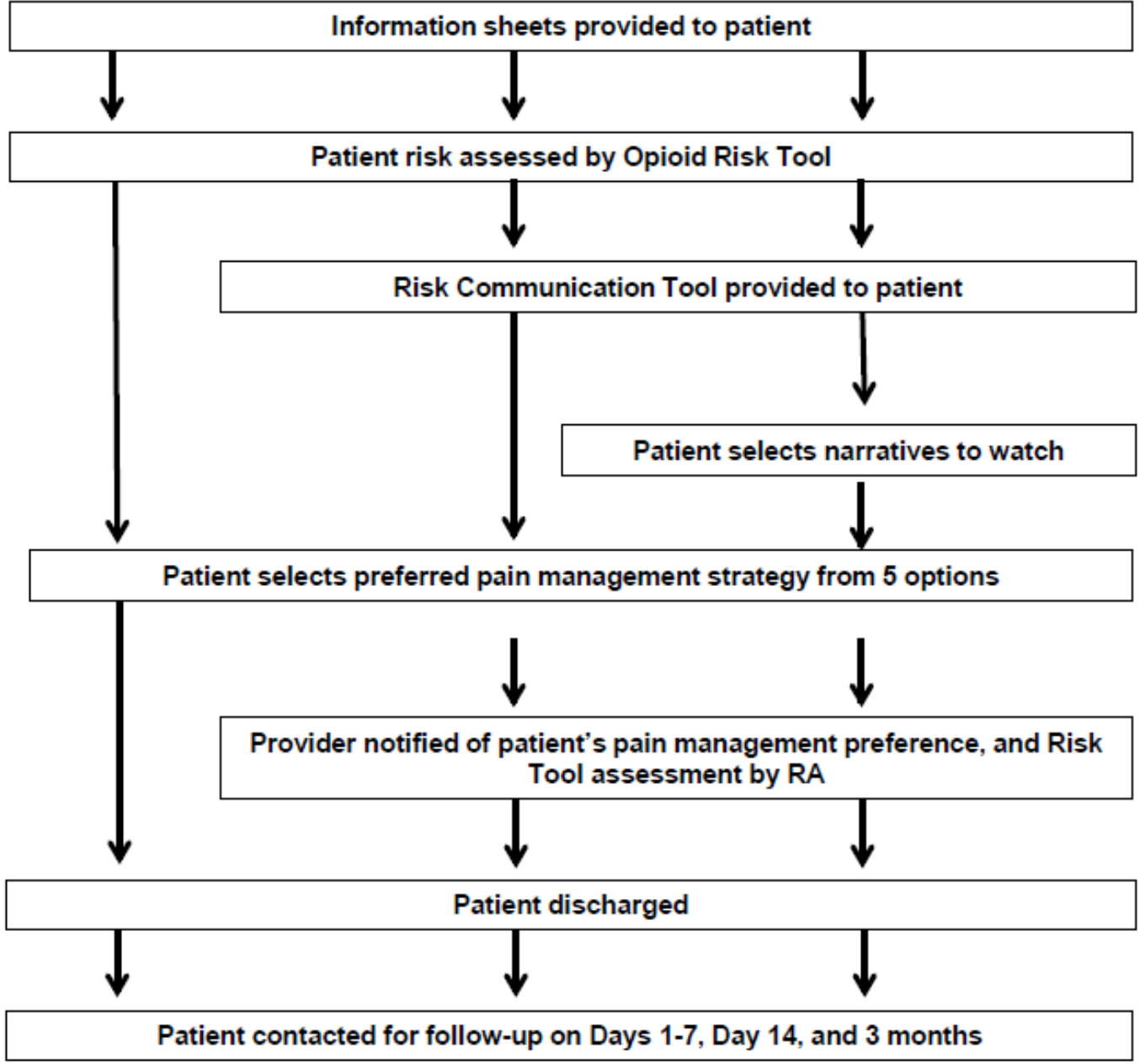

Figure 2

Flow diagram for Life STORRIED study. 


\section{Life STORRIED: Opioid Risk Assessment}
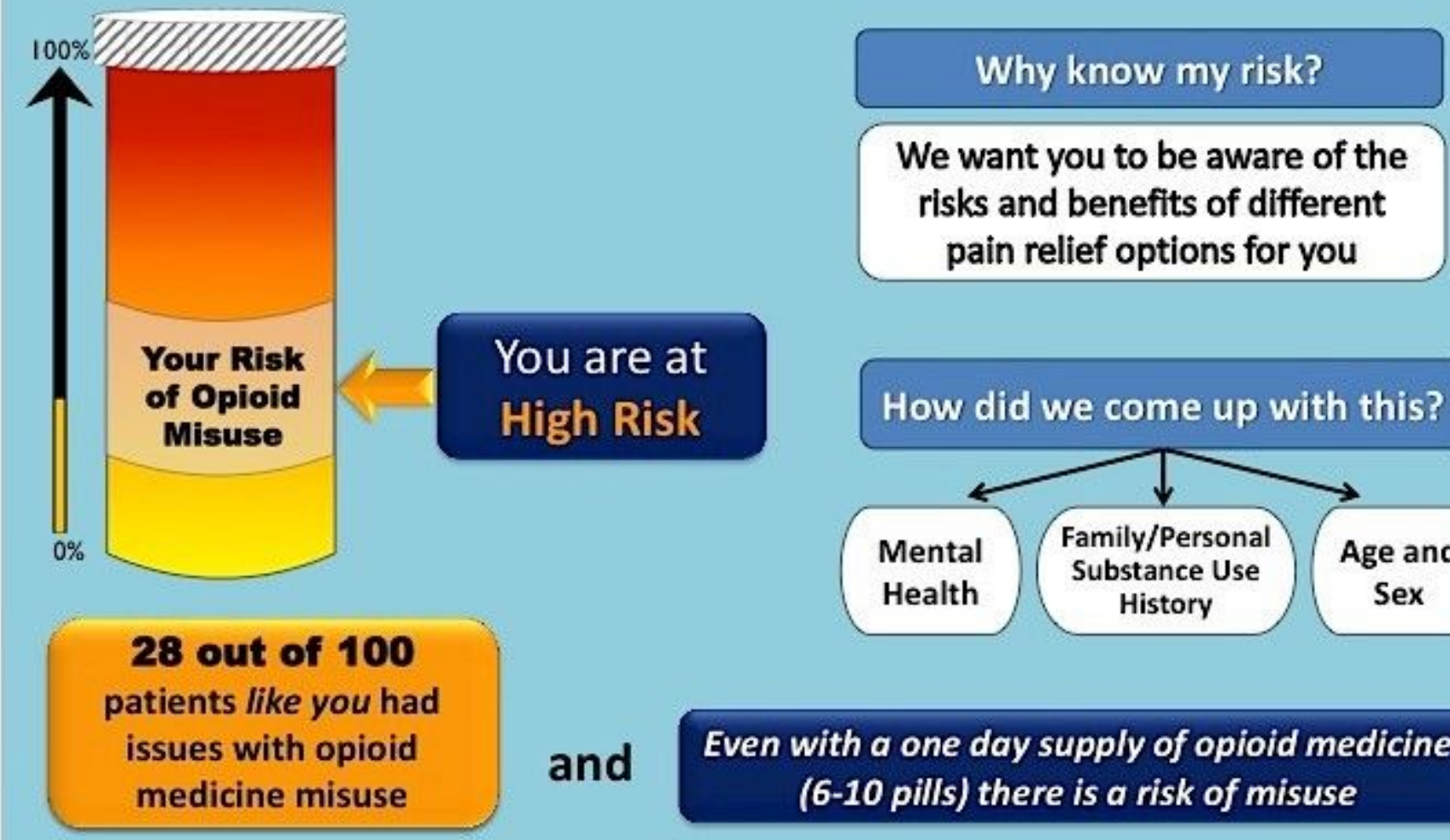

\section{You are at High Risk}

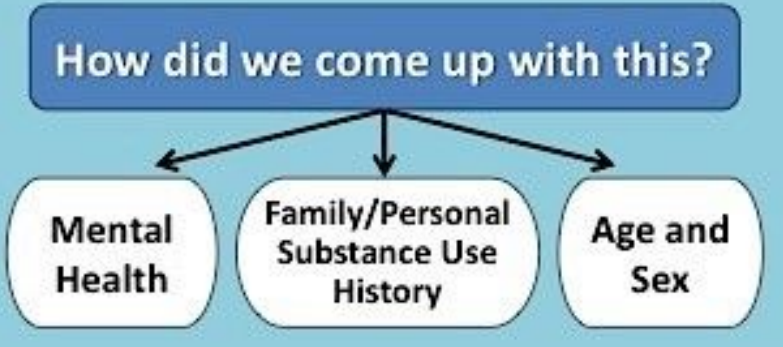

(6-10 pills) there is a risk of misuse

You have options to treat your pain. Some medicines do not cause addiction.

Talk with your doctor to find the best medicine for you.

Figure 3

Probabilistic Risk Tool (PRT), created by PI, based on responses to the Opioid Risk Tool assessment. 

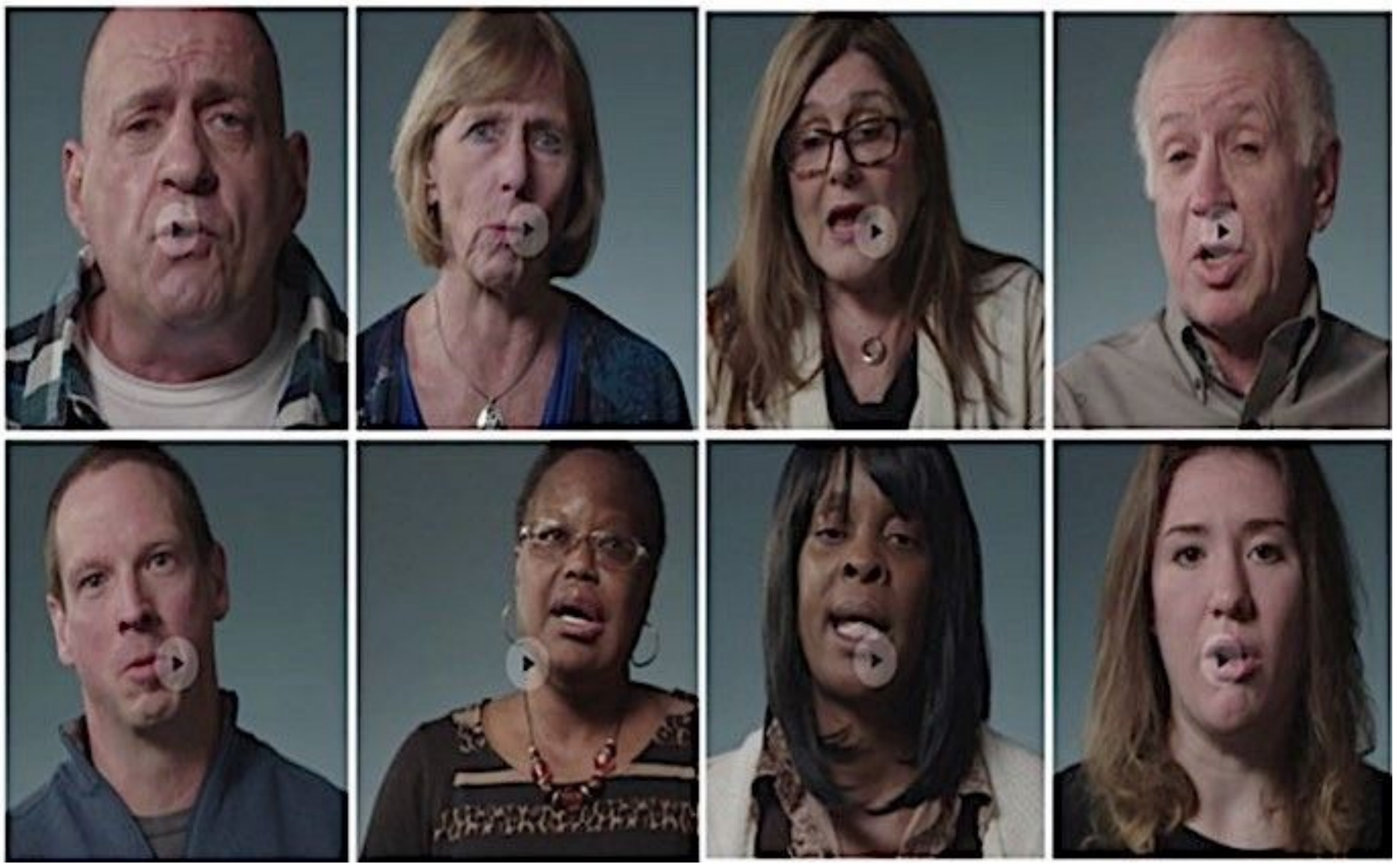

Figure 4

Online interface displaying personal video narratives included in the Narrative Enhanced Risk Tool (NERT).

\section{Supplementary Files}

This is a list of supplementary files associated with this preprint. Click to download.

- SPIRITChecklistLifeSTORRIEDProtocol11.7.doc 